\title{
A Review on Energy Consumption, Energy Efficiency and Energy Saving of Metal Forming Processes from Different Hierarchies
}

\author{
Mengdi Gao ${ }^{1}$, Kang He ${ }^{1, *}$, Lei Li ${ }^{2}$, Qingyang Wang ${ }^{1}$ and Conghu Liu ${ }^{1,3}$ \\ 1 School of Mechanical and Electronic Engineering, Suzhou University, Suzhou 234000, China; \\ mengdgao@163.com (M.G.); qingy_wang@163.com (Q.W.); 1ch339@126.com (C.L.) \\ 2 School of Mechanical Engineering, Hefei University of Technology, Hefei 230009, China; \\ accumulatelee@mail.hfut.edu.cn \\ 3 Antai College of Economics and Management, Shanghai Jiao Tong University, Shanghai 200030, China \\ * Correspondence: 1980evil@163.com; Tel.: +86-151-5621-8446
}

Received: 22 April 2019; Accepted: 5 June 2019; Published: 10 June 2019

check for updates

\begin{abstract}
Energy efficiency improvement and environmental impact reduction are emerging issues in the manufacturing industry. Aside from cutting, metal forming is also an important process in manufacturing. Metal forming is energy intensive because of the low energy efficiency of the used metal forming press. Although many literature reviews focused on the energy reduction and energy efficiency of machine tools, a comprehensive literature review of metal forming processes remains lacking because of the great difference between cutting machines and forming equipment. In addition, methods for energy efficiency and energy-saving still need to be promoted in metal forming. In this review, a novel hierarchy of the metal forming system was presented to describe the relationship among the equipment, process, and manufacturing system, providing a guideline of methods for energy efficiency and saving in metal forming. Then, existing energy consumption modeling and estimation theories and methods were discussed from two aspects. One is energy monitoring and modeling of metal forming equipment, and the other is process energy analysis of metal forming based on different parameters. On the basis of the hierarchy of the metal forming system, the present methods and technologies aiming to promote energy efficiency and energy saving effects were discussed from the aspects of equipment design and control, process optimization, and scheduling management and use. Thus, this review may serve as a reference for the decision-making of producers and managers to realize energy efficiency and energy saving at the system level. In addition, the major points that need attention are accurate energy models and control of forming equipment as well as the integrated optimization of equipment, process, and scheduling.
\end{abstract}

Keywords: energy consumption; energy efficiency; energy-saving; metal forming process; press

\section{Introduction}

The demand for energy and resources has increased with the fast development of the economy. Since 1990, the percentage of global energy consumption has increased by more than $30 \%$; in particular, the energy consumption of developing countries increased faster with their growth because of their low energy efficiency [1]. Industry is acting to promote economic development, which is a major contributor to energy consumption and environmental problems. Approximately one-third of the world's end energy is consumed by industry, and almost $40 \%$ of the total energy is translated to carbon emissions [2,3]. Nevertheless, manufacturing dominates the developing industry and thus consumes the largest energy. Manufacturing in 2015 accounted for nearly 57\% of energy consumption 
in China [4]. Mounting concerns on energy and resource depletion have rendered energy efficiency and energy saving technologies highly important.

Metal forming is a significant process in manufacturing; $70 \%$ of metals in the world are processed by metal forming, which has also been widely applied in the automotive and aviation industries [5]. However, in metal forming, high forming force is needed but the energy efficiency of forming equipment is low [6,7]. Therefore, metal forming consumes a large amount of energy because of its low energy efficiency.

In a production line/chain or a shop that consists of several metal forming presses, scheduling control is important for energy saving. Inappropriate scheduling leads to more idling time; consequently, more energy dissipation occurs. In consideration that energy consumption is the main contributor to carbon emissions during equipment operation, metal forming presses with considerable energy losses have become a large emitter of carbon dioxide [8,9]. Nowadays, the energy consumption reduction and energy efficiency improvement of metal forming have become urgent issues.

\subsection{Research Aim and Motivation}

Numerous studies have focused on methods and technologies for energy efficiency improvement and energy saving in manufacturing fields [10,11], and considerable efforts have been exerted to achieve green and environmental benign processes. Although some maturing methods and technologies are available for energy-intensive processes, such as machining processes [12-15], the energy reduction and energy efficiency improvement methods for machining may be not definitely practicable for metal forming because of the large difference between metal forming and machining processes as well as the various characteristic features of presses and cutting machine tools. Moreover, comprehensive reviews in metal forming are rare. Thus, the present review summarizes the existing energy consumption models and discusses methods for energy efficiency improvement and energy saving in metal forming to develop environmental-friendly metal forming presses in the future.

\subsection{Characteristic Features of Metal Forming Equipment}

A metal forming press is an equipment used to reshape or deform a metal through pressure. According to the design principle and working media, presses can be classified into three categories, namely, hydraulic press, mechanical press, and pneumatic press. Metal forming presses could be regarded as the composition of mechanical structure and control systems depending on their structural features.

The mechanical structure of a press is typically composed of a simple rectangular frame, and large and medium presses with a heavy body often contain two or four pillars and three crossbeams. The mechanical structure of some small presses is simple and integrated. The frame is the physical support and safety protection structure of a press in the forming process. The slide is the moving structure used for general-purpose forming work, which is driven by the execution unit in the control system. The slide guide system is used to avoid tilting of the slide during the operation of equipment [16]. The control system is composed of energy transfer and conversion units, an execution unit, and an operating device, which provide power for the press operations. During metal forming, the press provides a large pressure. Combined with the size of its actuator, the output force of the press would be very high. In particular, the hydraulic press could export very high forming force, which has been widely used in the manufacturing of large parts. Figure 1 shows the structural composition of a hydraulic press, and other types of presses have a similar composition as the hydraulic press. 


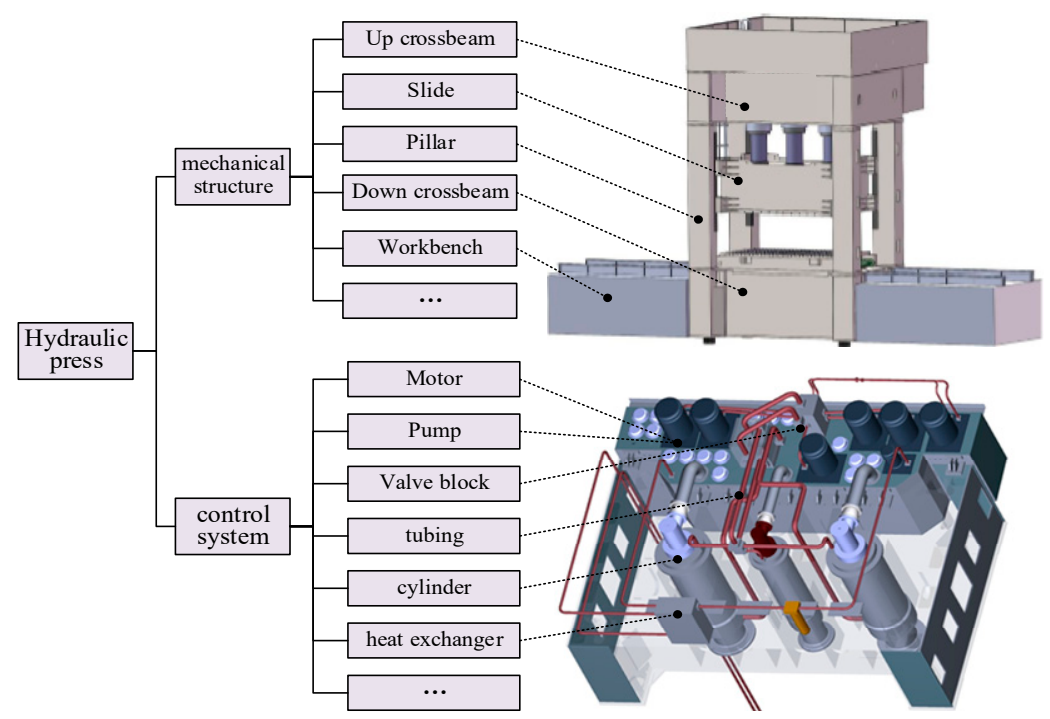

Figure 1. Structure and basic components of a hydraulic press.

According to the slide motion feature of the press, metal forming processes can be divided into a series of short operations as shown in Table 1 [7]. Sometimes, parts of these operations are involved in different metal forming processes. The feature of the slide motion is shown in Figure 2. Among them, the necessary operations are fast falling (FF), slow falling and pressing (SP), fast returning (FR), and slow returning (SR), and the others are alternatives for completing metal forming.

Table 1. Function features of each operation (Reproduced with permission from Li, L., et al., J. Clean. Prod.; published by Elsevier, 2016) [7].

\begin{tabular}{cl}
\hline Operation & \multicolumn{1}{c}{ Function Feature } \\
\hline Fast falling (FF) & Slide moves downward at a high speed to reach the workpiece \\
\hline Slow falling and pressing (SP) & Workpiece is formed at a given lower speed \\
\hline Pressure-maintaining (PM) & $\begin{array}{l}\text { High pressure is maintained for a given time to avoid the } \\
\text { springback of the parts }\end{array}$ \\
\hline Unloading (UL) & Pressure is released before moving upward \\
\hline Fast returning (FR) & Slide moves upward at high speed \\
\hline Slow returning (SR) & Slide moves back to the original position at low speed \\
\hline
\end{tabular}

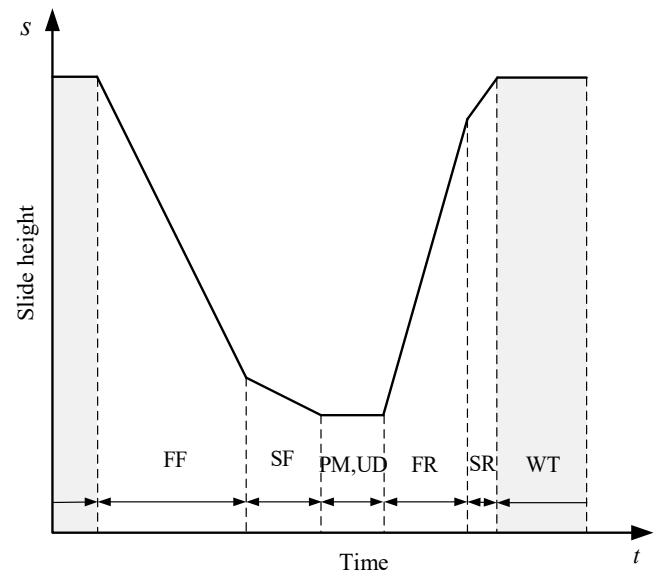

Figure 2. Height of the slide in a forming process. 
In a forming process, the highest power operation is SP. Thus, the installed power of a hydraulic press is designed to meet the needed highest power, but the operation time of SP is much shorter in the whole working process and the needed power of other operations is much less than SF, which usually leads to a mismatch between the needed power and installed power, especially for the large hydraulic press. In addition, the waiting time (WT) in two successive processes is unavoidable, which is used for the workpiece delivery. Once a hydraulic press is waiting, all pumps are unloaded in the drive system. All the input energy is wasted because the motor and pumps cannot be turned on and off frequently.

In consideration of the defects of the conventional presses, servo presses with flexible slide movement and low energy consumption have been used in the metal forming industry. Mechanical and hydraulic servo presses are two typical types of servo presses. The drive unit in servo presses is AC servo motor. The energy consumption of a servo press is only $10-20 \%$ of other press machines. However, for some high pressure demanded conditions in the metal forming process, big servo press with big motor is need. For the power limitation of the servo motor, the conventional presses are still widely used in conditions of high pressure demand. Therefore, the conventional press is one of indispensable parts in metal processing field.

\subsection{Scope of the Review}

Although servo presses have been used in metal forming processes because of their advantages of flexibility and energy efficiency, the conventional presses are still irreplaceable when considering process requirements and high-pressure conditions. However, large energy loss occurs because of the characteristic features of press operations during metal forming processes. Moreover, the energy consumption of hydraulic presses is larger than that of other types of metal forming presses. Therefore, this review focuses on the electrical energy consumption of presses mainly for metal forming processes.

Hence, this research focuses on reviewing the methods and technologies for energy consumption identification, energy efficiency improvement, and energy reduction in metal forming. Energy consumption can be understood and identified by energy model analysis and establishment. Energy efficiency improvement and energy saving could be achieved by direct energy reduction methods, such as controlling the process, efficient process planning, process time reduction, efficient components, and lightweight design. In addition, the indirect ways of increasing energy efficiency involve some energy-related improvements such as stability performance and productivity improvements. Given that the primary consideration in the manufacturing industry is product quality and productivity, all energy reduction strategies should be implemented without sacrificing quality or productivity. Both direct and indirect energy reduction methods and technologies are considered in this review and are classified according to their application.

\section{Hierarchical Approach for the Metal Forming Manufacturing System}

In a metal forming manufacturing system or a workshop, many presses are used for various manufacturing purposes. When the press is used in different processes, the energy consumption would be different. In addition, the corresponding energy efficiency and energy-saving methods vary in accordance with the level involved. Numerous studies have investigated the energy-efficient and energy-saving methods at different levels of the manufacturing system [17-19].

According to the special characteristic features of metal forming presses, the manufacturing system of metal forming is divided into four levels based on previous research: component/unit level, equipment level, process level, and manufacturing system level. In this hierarchy, the manufacturing system could be regarded as the integration of a series of forming processes. Each metal forming process is implemented on the press, and the press is assembled by a series of unit devices and components. A schematic view and features of the manufacturing system hierarchy for metal forming is shown in Figure 3. 


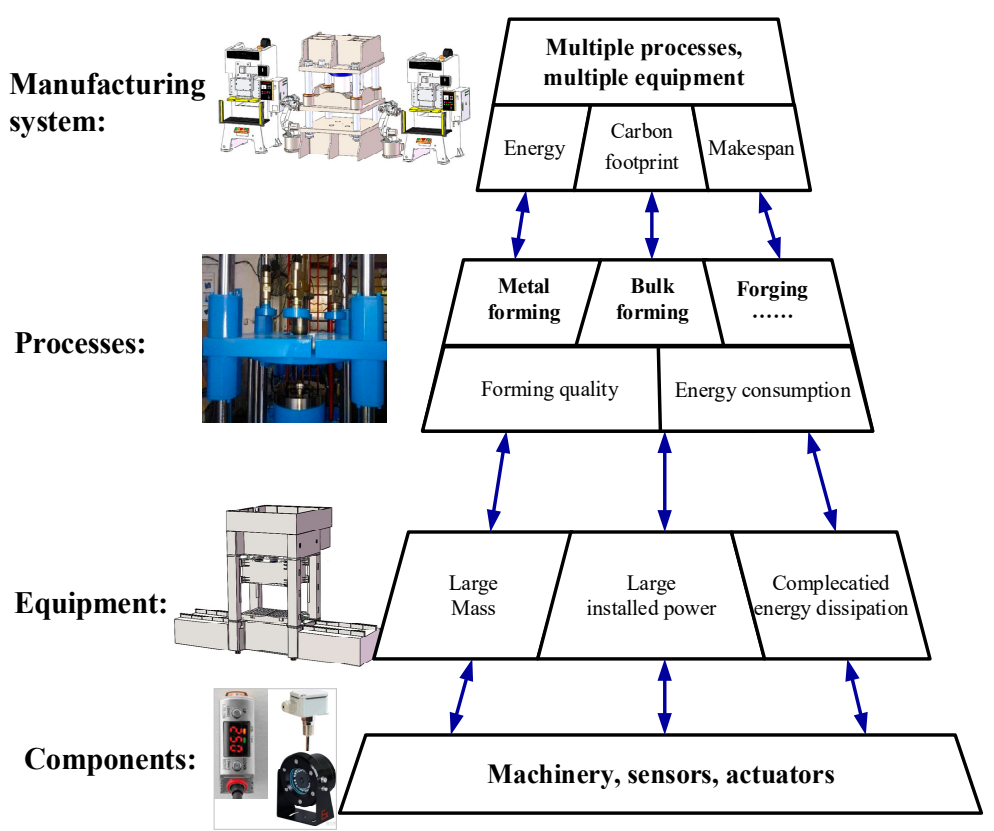

Figure 3. Schematic view and features of the manufacturing system hierarchy.

In this review, the methods and strategies for analyzing energy consumption, improving energy efficiency, and saving energy are explained in accordance with the manufacturing system hierarchy. The aim is to help metal forming managers conduct these energy-efficient and environmentally benign methods step by step. The energy efficient methods for cutting machine tools have many classifications $[20,21]$. On the basis of previous classifications of machine tools and the manufacturing system hierarchy of metal forming, three hierarchies are presented in this study. The detailed classifications of the hierarchical approach for metal forming equipment and processes are described in Table 2.

Table 2. Energy saving and environmental-friendly methods and technologies at different levels for metal forming.

\begin{tabular}{|c|c|}
\hline Classification & Detailed Strategy \\
\hline \multirow{5}{*}{$\begin{array}{l}\text { Energy consumption models and energy efficiency } \\
\text { improvement of a single press }\end{array}$} & $\begin{array}{c}\text { Monitoring and modeling, identification of energy } \\
\text { consumption }\end{array}$ \\
\hline & $\begin{array}{l}\text { Improving the energy efficiency of the } \\
\text { component/unit within the press }\end{array}$ \\
\hline & Reducing idle production time \\
\hline & Waste recovery within a press \\
\hline & Lightweight design of presses \\
\hline \multirow{3}{*}{$\begin{array}{l}\text { Optimization and control for energy reduction of } \\
\text { metal forming processes }\end{array}$} & Process energy modeling \\
\hline & Optimized process parameters \\
\hline & Process improvement \\
\hline \multirow{3}{*}{$\begin{array}{l}\text { Energy-efficient scheduling management and use for } \\
\text { multi-presses }\end{array}$} & Identified and structured decision problems \\
\hline & Energy modeling at multi-press level \\
\hline & Solution selection method \\
\hline
\end{tabular}

The first hierarchical approach is establishing energy consumption models and improving the energy efficiency of a single press. This hierarchy corresponds to the component/unit and equipment level of the manufacturing system hierarchy because the efficiency of the equipment could be improved 
by using more efficient component units such as the wide application of high-efficiency motors [22]. In this approach, measuring and identifying the energy consumption of the press is primary for energy efficiency improvement. Then, the energy consumption of the press is monitored, characterized, and modelled, and the system is decomposed into components at this level. Therefore, useful information on the energy consumption of presses could be obtained. The energy efficiency can be improved by directly reducing the energy loss or waste energy recovery. In addition, optimal design of presses is an indirect way of improving energy efficiency. The lightweight design of presses can both directly and indirectly improve the energy efficiency of presses.

The second hierarchical approach is optimization and control for the energy reduction of metal forming processes at the process level. Process parameters for optimization include changeable parameters (e.g., punch velocity, blank holder force, and lubrication), material parameters, and mold parameters. The process energy models could be established using the energy measuring and monitoring method or data obtained from the first level, which is basic for process optimization. Process energy can be reduced with product forming quality and production improvements without significant structural changes to the presses as well as prognosis of the energy consumption of different processes.

The last one is energy-efficient scheduling management and use for multi-presses. More than one forming process is usually needed in metal forming. Therefore, several presses can be equipped into a production line to complete the forming tasks at the manufacturing system level. The energy strategies in this hierarchical approach involve scheduling approaches of metal forming presses to increase energy efficiency. Decision problems and their features must be identified and described. The corresponding methods for operational production scheduling could be effective in manufacturing companies. Then, the scheduling management and use for the multi-press system are analyzed to discuss the potential of energy reduction and energy efficiency improvement at the system level.

These hierarchical approaches are arranged in accordance with the level of modification activity or improvement difficulty as well as the decision-making level. The energy-saving effects are various in different hierarchical approaches. Each approach can be used separately or in conjunction with other methods as shown in Figure 4. The research status at each individual level is reviewed and discussed in detail in the following sections.

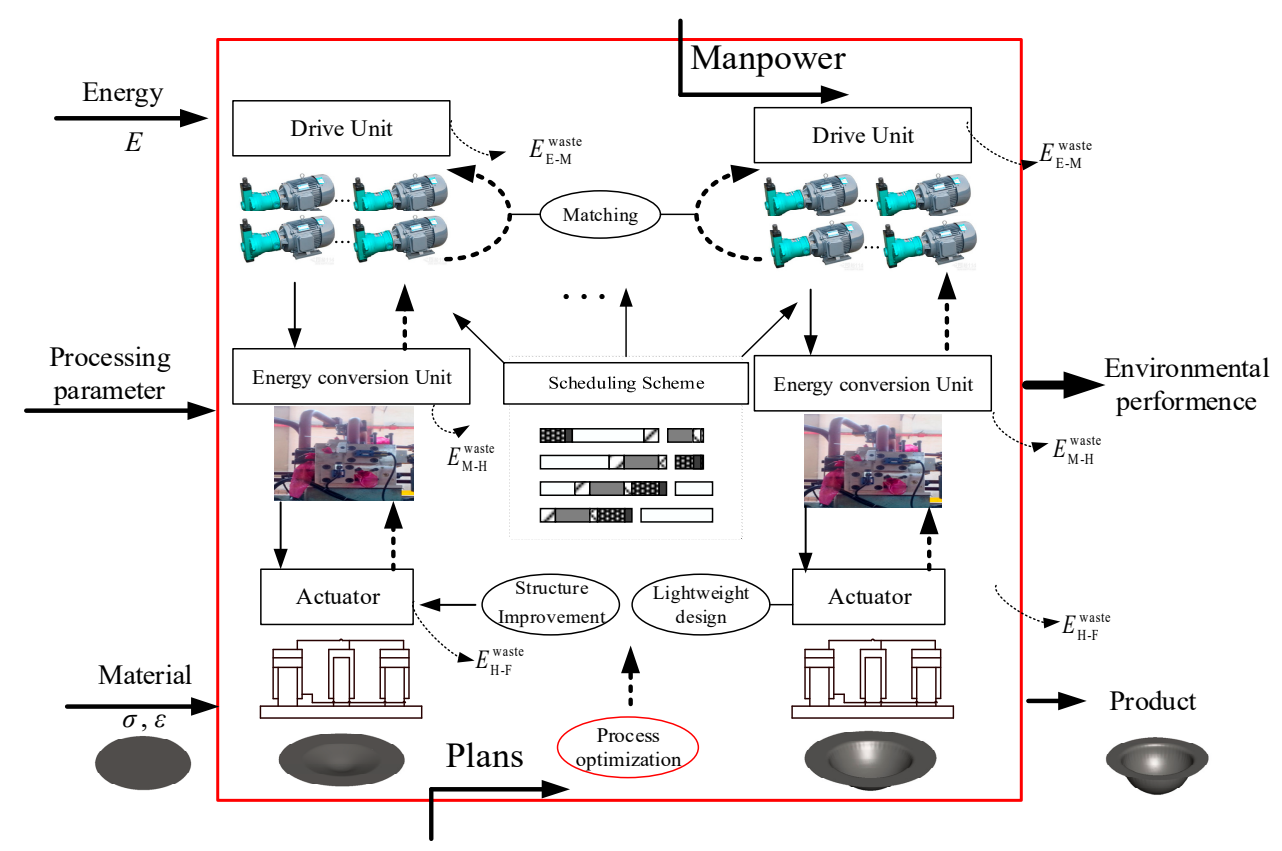

Figure 4. Energy saving strategies for metal forming press in the manufacturing system. 


\section{Framework for Energy Saving}

The review methods used in this research are shown in Figure 5, which is the guideline for this literature review. After defining the scope and purpose of this research, the review process could be divided into four main steps. First, the research theme or question should be specified, which could be described as a conceptualization stage. In this study, the main question is how to reduce energy consumption and improve energy efficiency in the metal forming process, which also involves the forming equipment and manufacturing system used. In addition, related environmental problems, such as carbon emissions, are also caused by energy consumption. Therefore, the search keywords for this review could be summed up as shown in Table 3. Second, a high number of relevant literature data were obtained by using the keywords and appropriate search strategies. Third, the current topics and issues were refined after reading and analyzing the searched literature critically in the evaluation phase. In the last phase, the findings were synthesized. The research process of the review includes iterative and circular literature analysis and synthesis process.

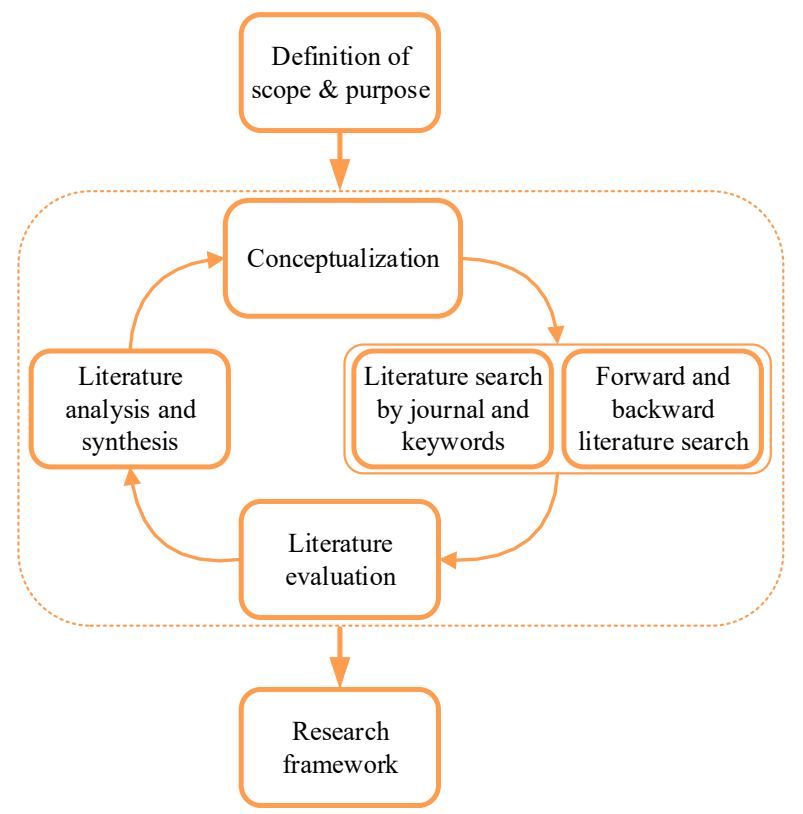

Figure 5. Phases of the research process.

Table 3. Keywords for the review.

\begin{tabular}{cc}
\hline Keyword 1 & Keyword 2 \\
\hline $\begin{array}{c}\text { energy consumption, energy efficiency, } \\
\text { energy-efficient, carbon emissions, light weight }\end{array}$ & metal forming process, press, hydraulic press, \\
scheduling
\end{tabular}

A methodological framework was derived from the previous hierarchical approach for the metal forming manufacturing system and the above research process of the review, providing an outline for the review. A descriptive flowchart for depicting the major steps of the proposed methodology is shown in Figure 6. In this research, the energy consumption analysis and energy models for metal forming equipment and process were first discussed to find the potential for energy reduction. Then, the methods and technologies for promoting the energy efficiency and saving from the aspects of design and control of metal forming equipment, process optimization, scheduling management, and use of the workshop were addressed in accordance with the proposed hierarchical approach. The detailed description of the flowchart is addressed as follows. 


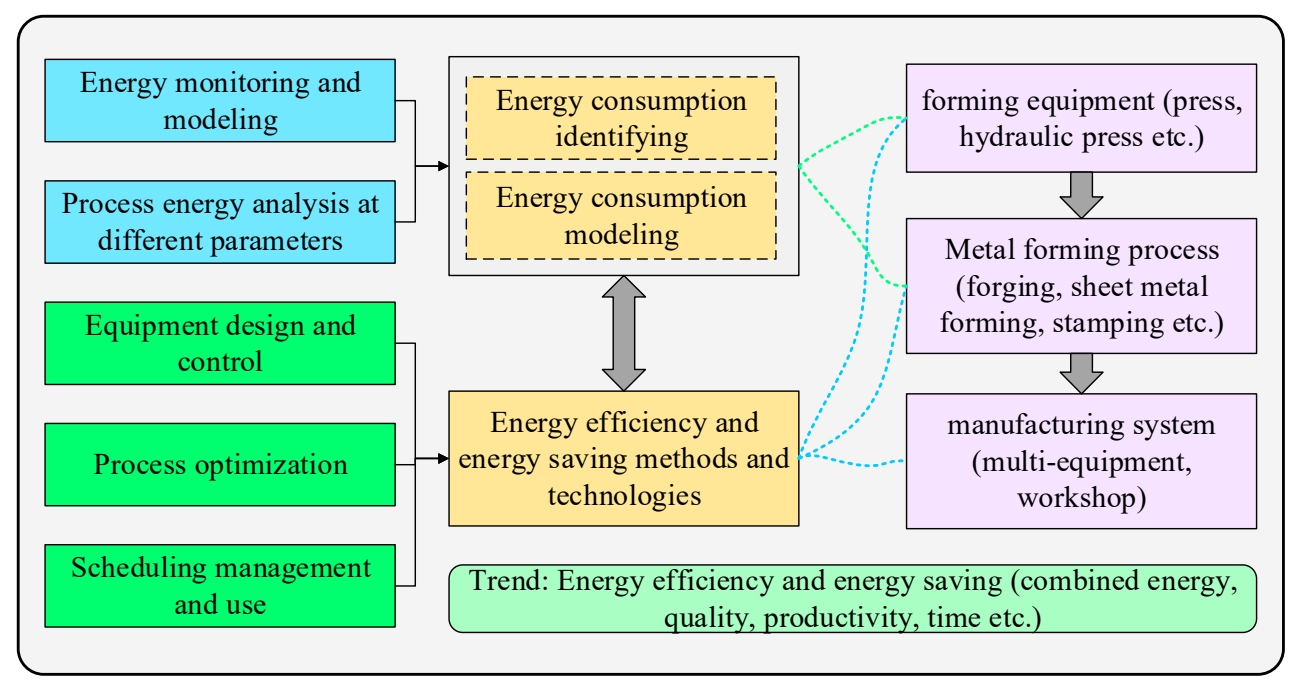

Figure 6. Methodological framework for the review.

Energy consumption features must be identified before investigating the energy-saving methods. In the beginning of the review, energy consumption was analyzed from the perspective of equipment and process. Currently, the technologies of energy and power measurement have become faster and more accurate for energy monitoring at different levels [23]. The existing energy models of forming equipment were discussed to find which element is the highest energy consumer. The elements could be the energy consumption units or hardware parts. However, the energy consumption of equipment varies with different process parameters because the demanded metal forming energy is influenced by variable process parameters. Hence, manufacturers need to deeply understand the energy consumption features of the processes to optimize efficiency improvement and energy saving methods.

The current methods and technologies for energy efficiency improvement and energy saving were addressed from different hierarchies. The energy efficiency and energy saving for a single press can be improved by direct or indirect ways to reduce the consumed energy of the equipment. At this level, the existing energy reduction methods enable us to know where and how to apply energy saving technologies. On the basis of the energy decomposition analysis of presses, the energy reduction strategies for a single press can be implemented by the efficiency optimization of the control system, which is the direct way to reduce energy consumption. For the large mass characteristic of the forming press, the structure optimal design is an efficient way to achieve energy saving.

The next level is the explanation and discussion of process optimization and improvement. The aim of this level is to discuss how to reduce the energy consumed in the metal forming process without sacrificing the product forming quality. The parameter optimization technologies for different metal forming processes and process improvement technologies were reviewed at this level. The energy consumption of the processes can be reduced by the strategies. The energy efficiency of forming equipment can also be further improved with a combination of the two levels of technologies.

More than one forming process is usually needed in metal shaping. Therefore, several presses form a press line to perform a series of forming processes, which are the traditional and common forms of production in the metal forming industry. The last hierarchy of energy saving and energy-efficient metal forming process is scheduling management and use for the multi-press system. Energy and environmental aspects need to be considered in scheduling the multi-presses stage to achieve energy-efficient scheduling management and use. Energy efficiency of the manufacturing system and energy-aware production planning and control could be involved at this level. Technologies for efficiency improvement at this level are from the systematic perspective of a workshop with a number of pieces of forming equipment. 


\section{Energy Monitoring and Modeling for Identifying the Energy Consumption of Metal Forming}

\subsection{Energy Monitoring and Modeling for Metal Forming Equipment}

The energy consumption of presses is measured at the primary power supply, and the obtained data represent the total energy consumption of all the components and units involved in the press. Therefore, this measured energy consumption value should first be divided into several independent energy elements. Each energy element could be tested directly by independent measurement or indirectly by using the difference between independent operations. Some researchers have performed on the decomposition of energy consumption values in detail, and the most representative classification of energy consumption elements of the hydraulic press was performed by Zhao et al. [6]. The decomposition of energy consumption in hydraulic presses is shown in Table 4.

According to the characteristic features of energy conversions within the hydraulic press in working processes, the energy consumption could be decomposed into six energy elements as shown in Table 4, which are performed by their corresponding components, as shown in Figure 7. Moreover, based on the energy dissipation features of the components, the energy consumption models of the main energy conversion components or units have been established, such as the motors and pumps [24,25], which means the energy characteristics of energy elements were quantified.

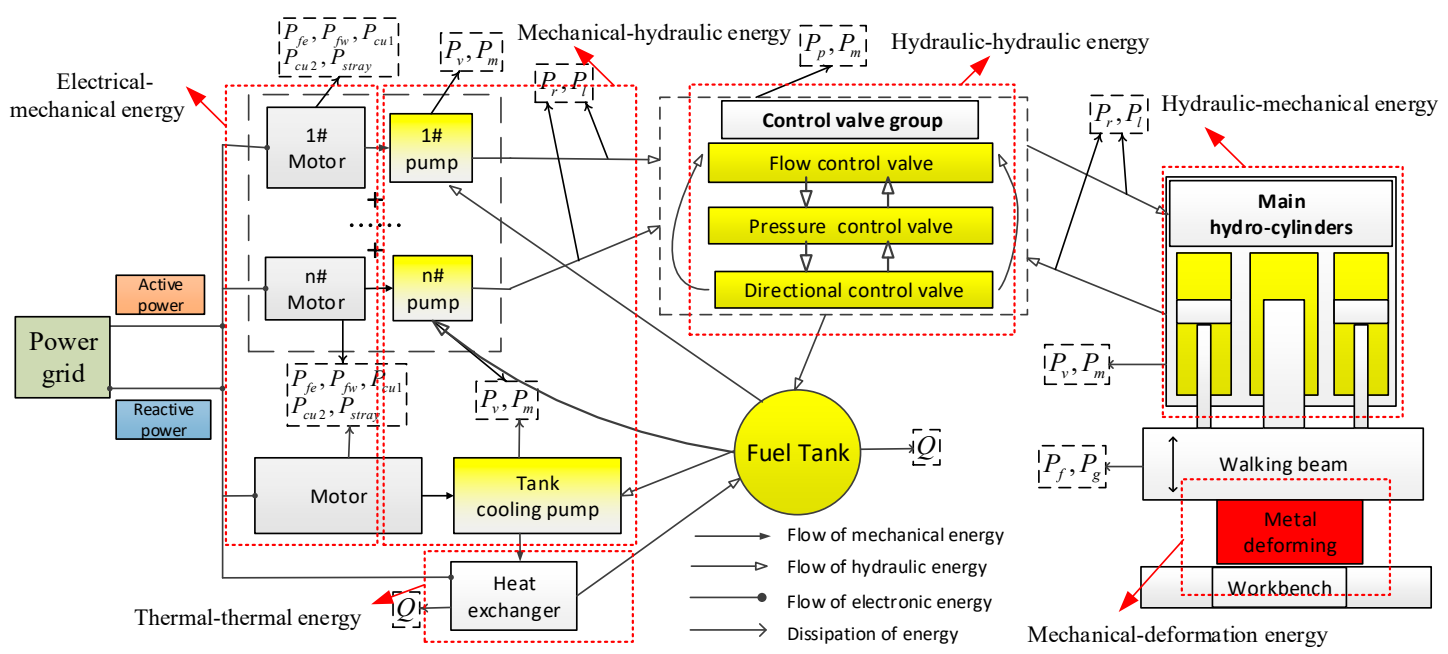

Figure 7. Energy flow and decomposition of energy consumption elements in hydraulic presses (Reproduced with permission from Gao, M., et al., Procedia CIRP; published by Elsevier, 2016) [26].

Different from the characterized classification of six energy consumption elements, another classification was proposed by Li et al. [7,27-29]. The energy consumption of a press was divided into two main portions in accordance with its operations as mentioned above. One of them is the active energy consumption by the actual forming processes, including the operations of FF, SP, FR, and SR as shown in Equation (1) [27]. The active energy consumption of operations is affected by process load or forming force. This energy element could vary with the process parameters and forming conditions.

$$
E_{\text {working }}=\sum_{m=1}^{\text {stage }(m)} \frac{\int_{t_{\text {stage }(m-1)}}^{t_{\text {stage }(m)}} F(t) v(t) d t}{\eta_{\text {stage }(m)}} .
$$


Table 4. Decomposition elements of energy consumption in hydraulic presses.

\begin{tabular}{|c|c|c|c|c|}
\hline Energy Conversion & Energy Elements & Input Parameters & Output Parameters & Energy Dissipation Model \\
\hline \multirow{2}{*}{ Electrical—mechanical energy } & \multirow{2}{*}{ Motors } & Electric voltage & Torque & \multirow{2}{*}{$E_{\mathrm{E}-\mathrm{M}}^{\mathrm{waste}}=\sum_{k} \int_{t}\left(P_{\mathrm{Fe}}(t)+P_{\mathrm{fw}}(t)+P_{\mathrm{s}}(t)+P_{\mathrm{Cu} 1}(t)+P_{\mathrm{Cu} 2}(t)\right) d t$} \\
\hline & & Electric current & Angular velocity & \\
\hline \multirow{2}{*}{ Mechanical-hydraulic energy } & \multirow{2}{*}{ Pumps } & Torque & Pressure & \multirow{2}{*}{$\eta_{\mathrm{M}-\mathrm{H}}=\eta_{m} \eta_{v}=\frac{\left(-C_{2} / q_{t}^{2}\right) p^{2}+p}{p+\left(C_{1} / q_{t}\right)}[24]$} \\
\hline & & Angular velocity & Quantity of flow & \\
\hline \multirow{2}{*}{ Hydraulic—hydraulic energy } & \multirow{2}{*}{ Valves, Auxiliaries, Pipes } & Pressure & Pressure & \multirow{2}{*}{$E_{\mathrm{H}-\mathrm{H}}^{\text {waste }}=\int_{t} \Delta p(t) q(t) d t$} \\
\hline & & Quantity of flow & Quantity of flow & \\
\hline \multirow{4}{*}{ Hydraulic_-mechanical energy } & \multirow{4}{*}{ Hydraulic cylinders } & \multirow{4}{*}{ Pressure Quantity of flow } & Pressure & \multirow{4}{*}{$E_{\mathrm{E}-\mathrm{M}}^{\mathrm{waste}}=\int_{t} p_{\mathrm{EM}}^{\mathrm{W}} d t=\int_{t} \frac{F_{\text {forming }}(t) v(t)}{\eta_{v c} \eta_{c m}} d t$} \\
\hline & & & Quantity of flow & \\
\hline & & & Force & \\
\hline & & & Moving speed & \\
\hline \multirow{2}{*}{$\begin{array}{l}\text { Mechanical—deformation } \\
\text { energy }\end{array}$} & Moved cross beam & Force & Stress & \multirow{2}{*}{$E_{\text {forming }}=\int_{t} F_{\text {forming }}(t) v(t) d t$} \\
\hline & Dies & Moving speed & Strain & \\
\hline \multirow[t]{2}{*}{ Thermal—thermal energy } & Heat exchanger & Temperature & Temperature & \multirow{2}{*}{$P_{\mathrm{T}-\mathrm{T}}=P_{\text {Tank }}+P_{\text {exchanger }}=K_{1} A_{1} \Delta T_{1}+K_{2} A_{2} \Delta T_{2}$} \\
\hline & Oil tank & Entropy flow & Entropy flow & \\
\hline
\end{tabular}


The other portion of energy consumption is needed for maintaining the basic operations of the press in WT or idle time between two forming processes. The power consumption during these periods is nearly constant, which is not easy to alter just by adjusting the process parameters. The unloading operation energy could be calculated using Equation (2). $P_{\mathrm{Ln}}$ is the unloading power of the forming equipment. Reducing the process time is the only way to reduce the energy consumption in this portion.

$$
E_{\text {idle }}=P_{\text {Ln }} \cdot t_{\text {idle }} .
$$

With the energy decomposition approach, energy models of presses can be established based on the process parameters and operation time. Through energy consumption modeling, the energy consumption of presses can be quantified and estimated, and the energy efficiency of presses can be identified.

\subsection{Process Energy Analysis of Metal Forming}

From the above-mentioned section, the energy consumption in different metal forming processes was measured, monitored, and quantified form the perspective of equipment, which is the direct electrical energy consumer, to investigate the energy reduction methods. However, the energy efficiency of the processes differs depending on the used press; thus, the process energy must be understood to evaluate the energy saving potential for enabling any improvements in energy saving and eco-efficiency at this process optimization level [30].

The process energy is the direct energy utilized for the deformation of metal material without considering the dissipation in energy conversion of forming equipment. In consideration that forming force is an equating external work with internal dissipation of energy, forming force prediction is an important research objective in the energy consumption modeling of metal forming processes [31,32]. Another way is directly developing analytical models for estimating the energy consumption of the material deformation. Many studies have developed comprehensive models that consider the process energy used for product manufacturing. The energy requirements and environmental impacts with different parameters in metal forming have also been analyzed [33]. Gao et al. have established energy models for evaluating the process energy of deep drawing and analyzed the effects of process parameters on energy consumption $[27,34,35]$. Ingarao et al. have reviewed the main topics concerning the energy and resource efficiency of sheet metal forming aiming at the emphasis of principal contributions [36]. The metal forming process energy is usually analyzed as a criterion in environmental impact evaluation or sustainability issues. The models for sustainability issues in metal forming processes were developed and analyzed by Rahimifard et al. [37-39].

Recently, hot stamping has been widely used and improved because of the urgent demand of reducing vehicle weight, improving crashworthiness and safety qualities, and producing ultra-high-strength steels and other lightweight materials for the manufacturing of automobile structural components $[40,41]$. However, compared with cold stamping, hot stamping is more energy intensive for heating the blank up to a certain temperature, which improves the energy consumption in heating processes [42]. Therefore, the energy consumption and environmental impacts of hot stamping are considered in the hot stamping industry. A method for energy and resource balancing was applied in hot stamping to analyze the energy and material utilization and to improve energy and resource efficiency in production [43]. Life cycle assessment was performed to measure the energy consumption in hot stamping, and results showed that improving the energy efficiency in oven curing is an efficient way to lower the carbon footprint; in addition, the thermal transfer and loss should be a priority for estimation [44].

Through energy analysis of metal forming, the minimum deformation energy can be determined, and the energy efficiency improvement potential was also defined. The environmental burdens of the metal forming processes were quantified for some large energy-consuming processes. 


\section{Energy Efficiency and Energy Saving Methods for Metal Forming in Different Hierarchies}

\subsection{Energy Efficiency Improvement and Energy Saving Methods for Forming Equipment}

Analysis of the characteristic features of metal forming presses showed that one of the major reasons for low energy efficiency of a hydraulic press is the power mismatch control in hydraulic systems. To address this problem, a series system energy matching control method used to adjust the output power and demand power has been reported.

The volume control electrohydraulic system is a widely used variable control system. The variable-frequency motors and servo motors are different types of variable-speed motors that are directly used to drive the actuator without the intermediate variable valves in the variable control system [45-47]. The demanded pressure and flow of the control system, and direction of working liquid are adjusted by the motors and pumps to solve the mismatch control problem and reduce energy consumption [48-50]. In addition, adaptive control approaches have been developed to fulfill the control performance of the volume control systems [51-54].

Another control strategy with particular potential to solve the mismatch problem is the application of digital hydraulics, which has recently achieved significant development. In a digital hydraulic system, a piston pump can be turned on or off by the valves to control the distribution of flow of the intervals between several outlets and to match the demanded flow of the cylinder [55]. Compared with traditional systems, digital hydraulics can reduce considerable energy loss, especially during partial load [56-58]. Further study could focus on two or more actuators controlled by these digital pumps in digital hydraulics to reduce the partial load and decrease the installed power of the drive system [59].

In consideration of the features of digital and mobile hydraulics in which a hydraulic drive system is shared by different actuators [60,61], an energy matching method has been proposed for the hydraulic press line. In this method, a drive system is composed of several motor-pumps, which is the only power unit to supply energy for the press. The drive system is decomposed into several drive zones to provide energy for different operations according to their load profiles [7,62]. The structure of the hydraulic press line and energy matching method is shown in Figure 8. In this method, the average energy consumption of each hydraulic press in the group is much less than that of a single hydraulic press, and the energy efficiency is improved. Moreover, the energy consumption in the forming stage has not significantly changed, whereas the consumption of hydraulic presses working in idle state has been reduced and even eliminated.

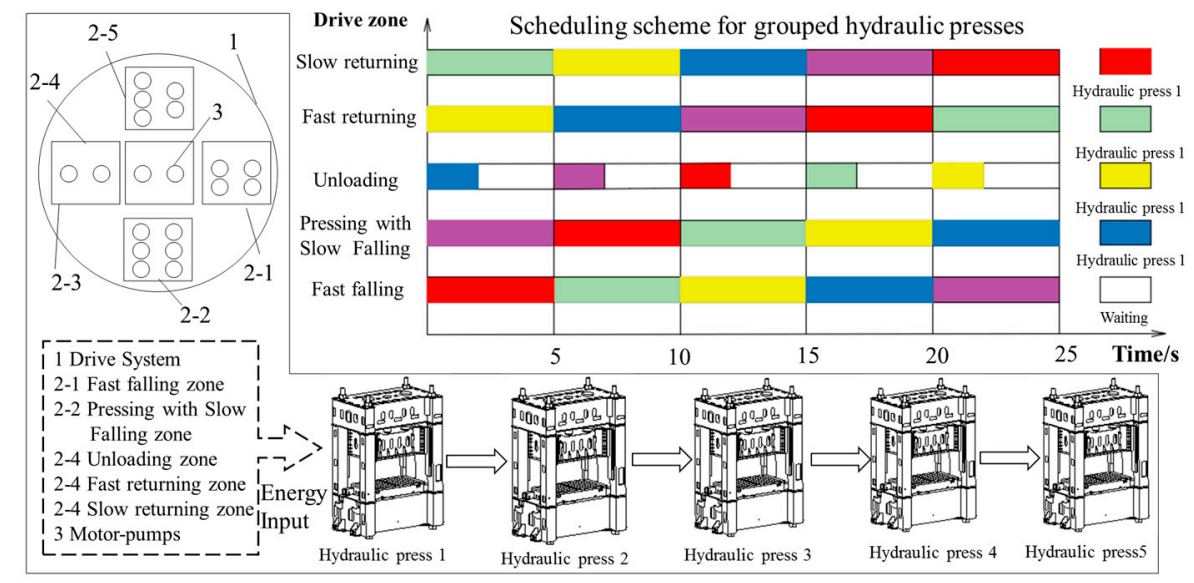

Figure 8. Configuration of grouped hydraulic presses and scheduling in the method (Reproduced with permission from Li, L., et al., J. Clean. Prod.; published by Elsevier, 2016) [7].

Another reason for the large energy loss of hydraulic presses is the wasted potential energy caused by the motion of the slider. The mass of the slider is substantial in large-sized presses compared with that of the entire machine. Therefore, a great amount of energy is wasted, which is caused by the 
advance and return movement of the slider in metal forming processes. About $20 \%$ of the total energy consumption is wasted in the downward motion of the slider [63]. However, this energy loss could not be reduced by the above method of press grouping.

Therefore, some regeneration methods were proposed to solve the energy loss problem. A hydraulic accumulator was applied to recover the kinetic energy, and a flywheel was used to store the inertia energy [64,65]. An ultra-capacitor can be used to improve the sluggish dynamic response $[66,67]$. The harvested potential energy of the perpendicularly moving load can be reused by the hydraulic drive systems when needed [68-71]. However, these regeneration approaches have two drawbacks. One is that the configurations of the equipment are more complicated for the conversion units installed. The other is the low energy efficiency of energy regeneration processes, including recovery and reuse. In consideration of these defects, an improved energy matching method for two combined hydraulic presses was proposed to utilize the potential energy. The drive system is shared by the two presses in different times to reduce the energy loss caused by the slide return operations, so that the energy efficiency of the drive system is improved [63,72]. Furthermore, this method derived a more energy-efficient system with a double-actuator in a hydraulic press to reduce the potential energy as shown in Figure 9. Compared with the current hydraulic press that undergoes services, the developed system exerts obvious energy-saving effect [73].

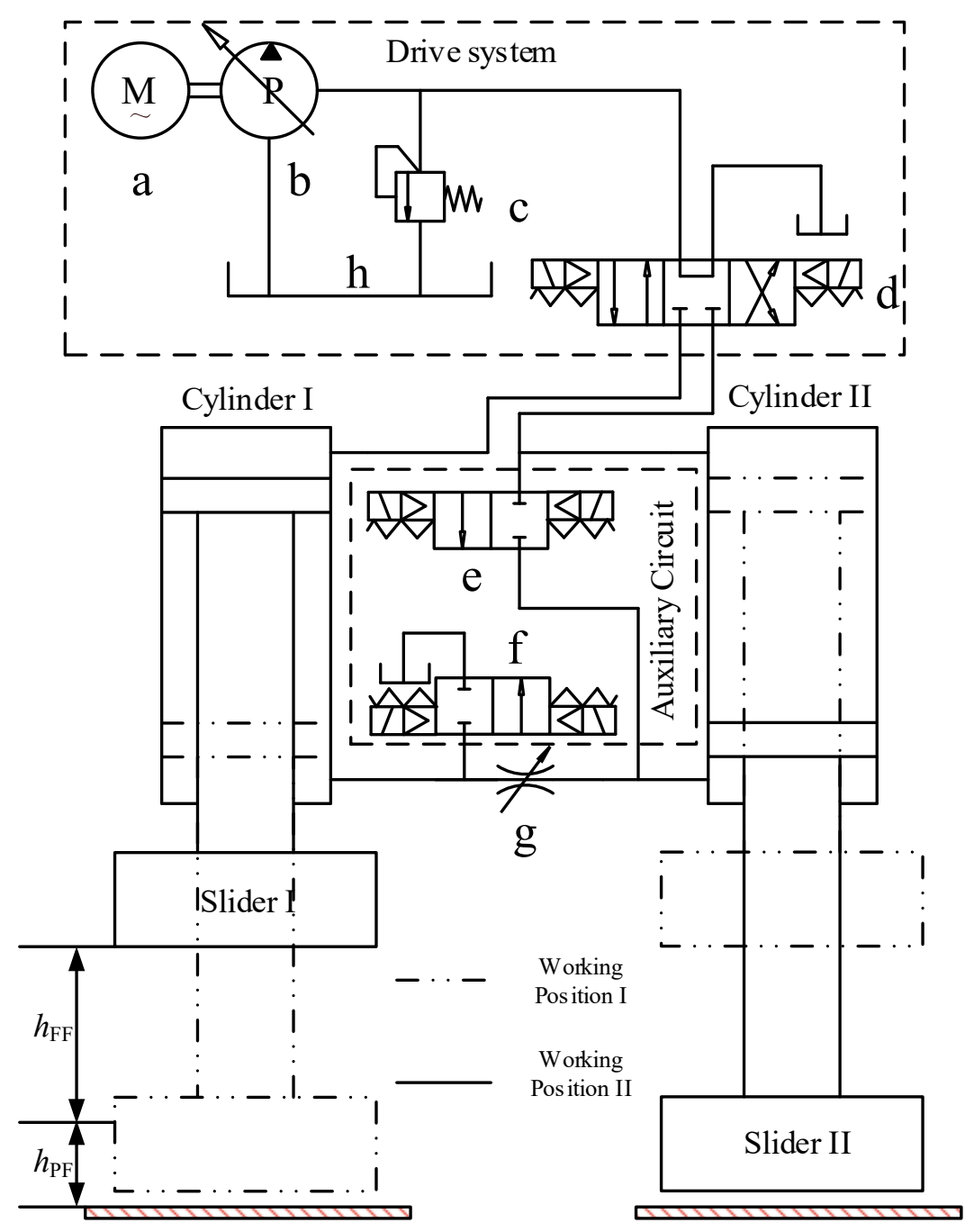

Figure 9. Schematic of the double-actuator hydraulic system. (Reproduced with permission from Li, L., et al., Mechatronics; published by Elsevier, 2017) [73]. 
The lightweight design of presses is the other energy saving strategy for single presses. The lightweight design of presses is a structural optimization to reduce the mass of equipment without sacrificing its structural stability. Therefore, the lightweight design could be regarded as a direct and indirect way to improve the energy efficiency of metal forming. The environmental impacts of the press at the machine design stage must be considered to obtain an energy-efficient press. Lightweight and friction reduction could lower the energy consumption in the operation process.

A large amount of energy wasted for the large mass of a slide could not only be regenerated by the above-mentioned control methods but also be reduced by the lightweight design, in which the mass of the slider or the moving element is reduced. As a result, the drive power consumption is also reduced. At present, the most typical lightweight design approach is the topology optimization, and the potential of this method is up to $20 \%[74,75]$. Li et al. proposed a novel self-adaptation bionic design method that combines topology optimization, size optimization, and geometric optimization [76,77]. The internal manufacturing structure of the slider was optimized to reduce its mass while considering the manufacturability. Zhang et al. optimized the structure of a large hydraulic press to realize manufacturing cost reduction, energy saving, and performance degradation minimization [16,78]. The energy consumption of the press can be significantly reduced with considerable mass reduction by the structure optimal design for press. Moreover, less material usage means lowering the manufacturing costs. The energy saving effect of lightweight could be small in one forming process, but the design of the equipment affects the energy efficiency during the life cycle of the press. Therefore, environmental influence must be considered at the primary design stage.

\subsection{Process Optimization for Energy Saving of Metal Forming}

Currently, most studies on process parameter optimization aim to improve the quality of products, which not only can directly reduce energy consumption but increase forming quality and productivity. Likewise, the robustness and stability improvement in the forming process can indirectly improve energy efficiency and help avoid significant energy loss. The uncertainties of forming quality and makespan can be reduced significantly and allow the press to endure high productivity parameters. Stochastic analysis and robust optimization help manufacturers and engineers deal with potential metal forming problems during the early stage of forming product and equipment design, by which more time and resources could be saved [79-81].

Optimization of process parameters is an efficient way to save energy in metal forming. The research on process optimization can be divided into three broad categories. The conventional process optimization was based on the metal plastic deformation theory and combined with the usage of modern numerical simulation technology. Numerical simulations can quickly predict all considerable issues of sheet metal forming, including energy consumption, defects, thickness, loads, and springback $[82,83]$. In this optimization method, the contributors of process parameters on forming quality and process energy were primarily discussed by using FE simulations and then combined with the optimization approach to solve the process problems by adjusting the main parameters of sheet metal forming [84-86].

Another way to optimize the process is the application of an orthogonal design, which is used for discussing multiple factors and multiple levels of an research object [87]. The orthogonal design is often used in conjunction with other methods to form an optimization system. The combination of FE simulations and orthogonal experimental design could be used to find the effect of process parameters on the deformation behavior of a sheet metal and to solve the process optimization problem of metal forming. A matrix of experiments was used in Gao et al.'s research to discuss the contribution of different process parameters on energy consumption in deep drawing [34]. In addition, the obtained results can be used for process optimization and selection of the manufacturing parameters. Using finite element simulations and orthogonal design, Padmanabhan et al. determined the influence of forming process parameters and optimized them to reduce the manufacturing cost $[88,89]$. The orthogonal design can also be used by integrating the artificial neural network, genetic algorithms, and response 
surface methods to develop a design and optimization system for metal forming processes in industrial production [90,91].

Multi-objective optimization has been widely used in parameter optimization to obtain the best group of process parameters that can produce the desired metal forming part without the defects of fractures, wrinkles, insufficient stretching, or thickness variations or has the minimum environmental impacts, such as low energy consumption and material cost. Many researchers have discussed the combination of response surface method, neural networks [92], genetic algorithms [93,94], and multi-objective optimization to solve the process problems of metal forming. Many process parameters need to be considered in metal forming optimization, and their impacts on the forming quality and energy consumption are often contradictory. Then, the unavoidable contradiction would turn the optimization of metal forming processes into a multi-objective problem [95-98]. To reduce the influence of a stochastic property of process parameters on forming quality, some studies used the conjunction of multi-objective stochastic approach and response surface methodology to obtain optimal process parameters in hot stamping [99,100].

\subsection{Energy-Efficient Scheduling Management and Use for Manufacturing System}

\subsubsection{Scheduling Management and Use for Energy Efficiency}

The initial product scheduling was performed to overcome the limited resources. In the manufacturing workshop and service industries, scheduling is an important issue because it determines the production orders and the relevant sequencing and timing on different machines [101,102]. In scheduling management, the execution of a production process is first determined. Meanwhile, the amount of process energy demand that affects the energy efficiency is also determined, which means assigning the high energy consumption jobs to more energy-efficient machines [103].

Improper production plans of subsequent production operations cause avoidable energy losses in a workshop or production system. Intelligent production planning can reduce buffers in production to directly avoid the energy loss. Reducing the energy consumption can improve the energy efficiency of the manufacturing system, and the preconditions in the production should not be reduced. Therefore, production scheduling is an efficient approach to improve the energy efficiency of an enterprise.

Many review papers have addressed and generalized the scheduling for energy efficiency from different perspectives [103-107]. However, the explanations and investigations of the analysis concerning scheduling issues to improve energy efficiency are not in great detail because of the broad scope of the review study. Previous knowledge concerning energy-saving scheduling is limited but growing. The present strategies of scheduling management and use for energy efficiency can be classified into the following aspects according to the emphasis of scheduling.

Reducing the energy consumption caused by standby of the equipment is highly effective to improve the energy efficiency of the production system. The energy used for the machines keeping standby for waiting jobs accounts for approximately 10-25\% [108]. Controlling the shut down of a machine appropriately can reduce energy consumption effectively [109]. Previous research showed considerable energy savings by coordinating rules and a turn off/on strategy in the manufacturing process [110-112]. However, the interval of the workpiece average arrival time and the production batch should be considered in turn off/on operations to determine whether the energy consumption of turn off/on is less than the standby power consumption or not because frequent turn off/on will prolong the maximum completion time and even affect the stability of machines [113,114].

Dispatching production orders to avoid energy intensive is another way to realize energy efficient scheduling. The arrangement of workpiece machining procedure influences the energy consumption significantly $[115,116]$. The bottleneck process in a workshop determines the maximum workshop capacity, which also makes the production line lose balance. The WT of the downstream equipment in bottleneck process would be longer. Then, the standby energy consumption would be increased. Many high-power demanded processes are operating simultaneously, which would cause the shop 
floor power to peak $[117,118]$. The optimization of process sequence can improve the utilization rate of machines. In addition, the WT and makespan of task processing would be reduced by batch production. The process energy intensive can be avoided and thus improve energy efficiency [119-124].

Selecting the optimal machine tools for operation is also a significant approach to improve the energy efficiency of scheduling. Sometimes, the same job can be machined in different equipment and obtain the same required quality, but different equipment consume different amounts of energy because of their different energy consumption features [125]. The multi-objective scheduling method can be used for selecting machines and determining the proper processing routine while considering the energy consumption in flow shops [126-130]. Selecting the optimal processing equipment and arranging reasonable processing routes is an efficient way to improve energy efficiency.

Other studies also used optimization to achieve energy efficiency improvements in scheduling. For example, jobs are assigned to machines considering their energy requirements [131]. Adjusting the processing speed of machines can also improve the energy efficiency [132-134]. Moreover, integrated optimization of processing parameters and scheduling is another approach to achieve energy saving [135-138].

\subsubsection{Energy-Efficient Scheduling of Multi-Equipment}

On the basis of the above-mentioned scheduling management and use for energy efficiency, scheduling is a suitable method for energy efficiency improvement and energy saving in manufacturing systems and thus can contribute to the sustainable production of goods. However, the proposed energy-efficient scheduling method is mostly for machine tools, especially for cutting machines. Significant differences exist between forming presses and machine tools, as stated in the previous sections. Therefore, the following content provides a detailed analysis of energy-efficient scheduling for multi-presses.

In Section 5.1 energy efficiency improvement and energy saving strategies for single press, the energy matching method was implemented by press grouping [7]. Through matching the output power of the drive unit in equipment and the demanded power of process operations, the result showed a significant energy reduction, but the drawback of this method is that the makespan was extended compared with the consumed time of each press operating independently. After reviewing previous studies on machining workshop, we found that energy saving by considering the configuration of the drive system when optimizing the scheduling of several presses is a promising method for energy saving.

Using the energy flow of the units in each press, Li et al. proposed an improved scheduling approach to balance the makespan and the energy consumption [139]. In this approach, the physical structure and drive system of the press in a production line are separated. Then, the physical structures named actuators are grouped to share a redesigned drive system by a valve matrix. The drive system consists of several motor-pumps that can supply energy to each actuator individually, whereas the valve matrix is composed of several on-off valves. The motor-pump can drive an actuator on the condition that the corresponding valve in the valve matrix is open. The configuration of the improved scheduling system is shown in Figure 10. The status of the matrix and the configuration of the drive system depend on the scheduling of the system. Based on this configuration, formulations of energy consumption and the makespan in the multi-press system were obtained by employing the energy flow of the energy conversion units at the single press level. This scheduling model considers two objectives, i.e., energy consumption and makespan can be solved by changing the configuration of the drive system. Finally, the optimal solution that can minimize these two objectives can be output. 


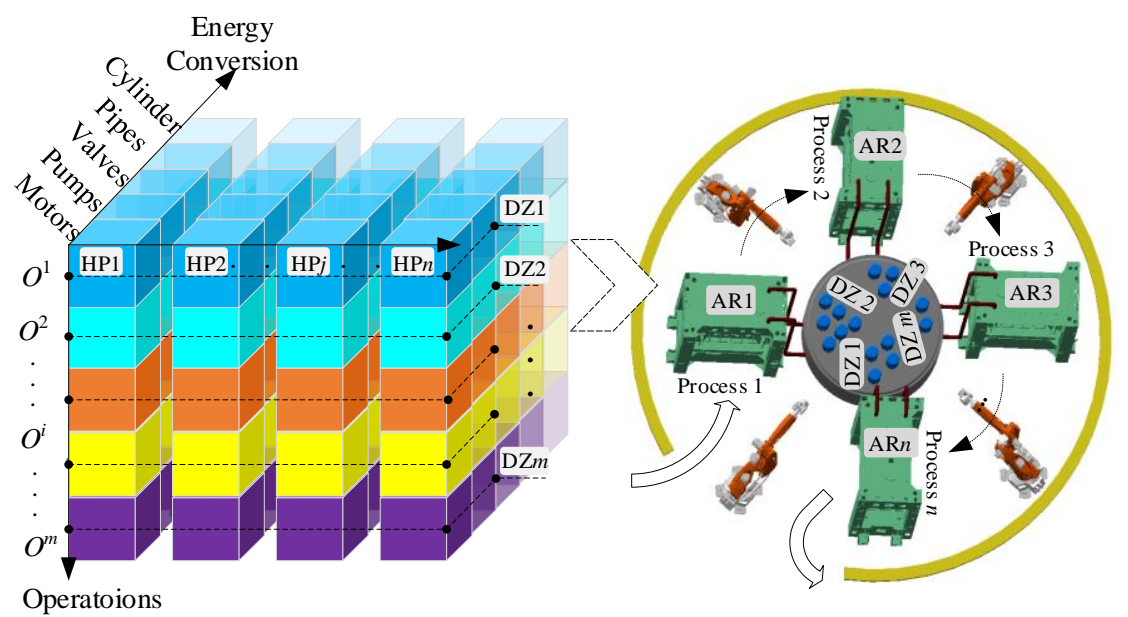

Figure 10. Configuration of the improved scheduling system and the energy flow (Reproduced with permission from Li, L., et al., J. Clean. Prod.; published by Elsevier, 2017) [139].

Based on the results, it can be found that the duration of the forming operation is the decisive factor of the makespan of the multi-press system. However, the duration of this operation has great effects on the forming quality. To shorten the duration, the relationship between the energy consumption and the forming parameters should be identified in the future.

\subsection{Discussions and Challenges}

Existing methods and technologies were reviewed and discussed from different hierarchies to provide a reference and clarify the challenges in energy efficiency and saving during metal forming. The improvement potentials of previous methods for energy saving and energy efficiency in different hierarchies are illustrated in Table 5. The deficiencies of each method were also discussed to indicate the problems and challenges for future studies.

Table 5. Potential and deficiencies comparison of the reviewed energy saving and energy efficiency improvement methods in different hierarchies.

\begin{tabular}{|c|c|c|}
\hline $\begin{array}{l}\text { Energy Efficiency and Energy Saving } \\
\text { Methods and Technologies }\end{array}$ & $\begin{array}{l}\text { Potential for Energy Efficiency } \\
\text { Improvement and Energy Saving }\end{array}$ & Deficiencies \\
\hline Equipment design and control & Considerable large & $\begin{array}{l}\text { - Some limitations in these methods for } \\
\text { equipment, and high costs for applications such } \\
\text { as changing some energy elements } \\
\text { or components. } \\
\text { - Some methods should be applied in the design } \\
\text { stage of the equipment and cannot be } \\
\text { implemented on old equipment }\end{array}$ \\
\hline $\begin{array}{c}\text { Process optimization for energy } \\
\text { saving }\end{array}$ & Relatively small & $\begin{array}{l}\text { The energy saving potential is very small with } \\
\text { parameter optimization alone, and the forming } \\
\text { quality may be sacrificed if only the energy } \\
\text { efficiency is improved. } \\
\text { The adjustment of some parameters is } \\
\text { constrained by the deigned products and } \\
\text { forming equipment, such as the parameters } \\
\text { of molds. }\end{array}$ \\
\hline Scheduling management and use & Very large & $\begin{array}{l}\text { - The energy saving potential is very large in the } \\
\text { workshop, but the flexibility is not good in } \\
\text { these methods. } \\
\text { The manager and producer need to consider the } \\
\text { comprehensive situation of the workshop, } \\
\text { which increases the ability demand of the } \\
\text { decision maker. }\end{array}$ \\
\hline
\end{tabular}


Table 5 shows that more elements and factors are considered in energy saving strategies. Larger potential would be achieved, but the generality and flexibility of the strategies would be decreased. Despite their deficiencies for energy efficiency improvement and energy saving of metal forming processes, all existing methods and technologies can provide reference for future research. The following points present challenges that need to be considered in future studies:

(1). Energy consumption analysis and modeling identifies which element is the main factor influencing energy consumption. Understanding the energy consumption features is most necessary for energy saving goals. Therefore, obtaining accurate data and exact analysis are extremely needed to establish accurate energy models.

(2). Energy analysis of metal forming processes determines the minimum deformation energy and defines the energy efficiency improvement potential. The environmental burdens of the metal forming processes were quantified for some large energy-consuming processes. Further studies on the energy consumption of metal forming processes can focus on applying the current methods to complex profiles in industrial manufacturing. These methods can be extended by integrating with the load profiles of different types of forming equipment.

(3). In addition, robust design of press cannot directly contribute to energy consumption but help allow higher productivity. Similarly, increases in natural frequency and process stability can indirectly contribute to energy efficiency improvement by improving the performance without significant loss of energy. They allow the press to endure high productivity parameters. The effect of lightweight and robust machine tool structure can be small in one cycle run, but the design of the machine tool affects energy efficiency throughout the lifetime of the press. Thus, energy efficiency and environmental concerns must be considered from the initial design stage.

(4). Metal forming processes were optimized through many optimization methods. Nevertheless, the energy consumption and environmental impact should not be neglected in process optimization. In consideration of relevant issues such as low carbon manufacturing and sustainable development, energy consumption must be considered as an optimization objective in further investigations of metal forming optimization. The relevant knowledge within this research field is still lacking at present.

(5). Furthermore, given that energy saving operation can be achieved individually by each strategy, an integration of these strategies under the perspective of manufacturing system hierarchy can be developed to implement energy management and control at the system level. Thus, energy-efficient manufacturing can be further realized.

\section{Conclusions}

Nowadays, the demand for energy-efficient and environmentally friendly manufacturing processes is high. Metal forming processes are important in manufacturing but are energy intensive because of the low energy efficiency of the used metal forming press. This review may serve as a reference for finding proper and effective methods and technologies to solve the energy inefficiency and energy dissipation problems in metal forming fields.

In this review, a novel hierarchy is presented for providing a direction and steps for the discussion of energy modeling, energy efficiency improvement, and energy saving methods at different manufacturing levels. Each method in different hierarchies can be used alone and in conjunction with others. However, these methods at different levels have different deficiencies in their applications. The improvement potentials for energy saving and energy efficiency in the system are very high, but the flexibility of the application of technologies at higher level are not satisfactory. In addition, they are difficult to directly apply to different manufacturing systems.

To achieve metal forming processes with high energy efficiency, more efficient equipment should survive in industry markets. Therefore, the energy efficiency and environmental influence of the equipment should be considered in the design stage. Accurate energy models and control of forming 
equipment are still needed, and a precise process energy analysis for complex profiles is also essential. The energy consumption and environmental impact as well as the load profiles of different types of equipment should be synthetically considered in the process optimization and scheduling of the manufacturing system. On the basis of this review, future studies on energy efficiency and energy saving should be at the system level. Therefore, manufacturers and producers must understand the equipment, process, and scheduling management to realize environmental-friendly metal forming processes.

Author Contributions: M.G. wrote the paper. K.H. designed the logic of the paper. L.L. developed the structure of the paper. Q.W. and C.L. contributed overall evaluation and revised the paper.

Funding: This research was funded by [key projects of natural science research in colleges and universities of Anhui province China] grant number [KJ2018A0451], [Suzhou Science and Technology Project] grant number [SZ2017GG28], [Suzhou College Scientific Research Foundation Project] grant number [2017JB03], [Suzhou Engineering Research Center for Collaborative Innovation of Mechanical Equipment] grant number [SZ2017ZX07], and [Suzhou College Teacher Application Ability Development Workstation] grant number [2018XJYY01].

Conflicts of Interest: We declare that we have no financial or personal relationships with other people or organizations that can inappropriately influence our work. We confirm that none of the material in the paper, in whole or in part, has been published or is under consideration for publication elsewhere. All the authors listed have approved the manuscript.

\section{References}

1. BP Statistical Review of World Energy. Available online: https://www.bp.com/zh_cn/china/reports-andpublications/bp_2016.html (accessed on 1 June 2016).

2. Cai, W.; Lai, K.; Liu, C.; Wei, F.; Ma, M.; Jia, S.; Jiang, Z.; Lv, L. Promoting sustainability of manufacturing industry through the lean energy-saving and emission-reduction strategy. Sci. Total Environ. 2019, 665, 23-32. [CrossRef] [PubMed]

3. Ingarao, G.; Ambrogio, G.; Gagliardi, F.; Di Lorenzo, R. A sustainability point of view on sheet metal forming operations: Material wasting and energy consumption in incremental forming and stamping processes. J. Clean. Prod. 2012, 29, 255-268. [CrossRef]

4. National Bureau of Statistics of the People's Republic of China. Available online: http://www.stats.gov.cn/tijj/ ndsj/2017/indexch.htm (accessed on 12 October 2017).

5. Zhong, J.; Zhao, K.; Liu, Z.; Li, X. Review of the research on low carbon manufacture of metal-forming equipment and future development. J. Hefei Univ. Technol. (Nat. Sci.) 2012, 35, 1594-1600.

6. Zhao, K.; Liu, Z.; Yu, S.; Li, X.; Huang, H.; Li, B. Analytical energy dissipation in large and medium-sized hydraulic press. J. Clean. Prod. 2015, 103, 908-915. [CrossRef]

7. Li, L.; Huang, H.; Liu, Z.; Li, X.; Triebe, M.J.; Zhao, F. An energy-saving method to solve the mismatch between installed and demanded power in hydraulic press. J. Clean. Prod. 2016, 139, 636-645. [CrossRef]

8. Cao, H.; Li, H.; Cheng, H.; Luo, Y.; Yin, R.; Chen, Y. A carbon efficiency approach for life-cycle carbon emission characteristics of machine tools. J. Clean. Prod. 2012, 37, 19-28. [CrossRef]

9. Shen, L.; Sun, Y. Review on carbon emissions, energy consumption and low-carbon economy in China from a perspective of global climate change. J. Geogr. Sci. 2016, 26, 855-870. [CrossRef]

10. Cai, W.; Liu, C.; Lai, K.; Li, L.; Cunha, J.; Hu, L. Energy performance certification in mechanical manufacturing industry: A review and analysis. Energy Convers. Manag. 2019, 186, 415-432. [CrossRef]

11. Napp, T.A.; Gambhir, A.; Hills, T.P.; Florin, N.; Fennell, P.S. A review of the technologies, economics and policy instruments for decarbonising energy-intensive manufacturing industries. Renew. Sustain. Energy Rev. 2014, 30, 616-640. [CrossRef]

12. Hasanbeigi, A.; Arens, M.; Price, L. Alternative emerging ironmaking technologies for energy-efficiency and carbon dioxide emissions reduction: A technical review. Renew. Sustain. Energy Rev. 2014, 33, 645-658. [CrossRef]

13. Yoon, H.S.; Kim, E.S.; Kim, M.S.; Lee, J.Y.; Lee, G.B.; Ahn, S.H. Towards greener machine tools-A review on energy saving strategies and technologies. Renew. Sustain. Energy Rev. 2015, 48, 870-891. [CrossRef]

14. Sciacovelli, A.; Verda, V.; Sciubba, E. Entropy generation analysis as a design tool-A review. Renew. Sustain. Energy Rev. 2015, 43, 1167-1181. [CrossRef] 
15. Salonitis, K.; Ball, P. Energy Efficient Manufacturing from Machine Tools to Manufacturing Systems. Procedia CIRP 2013, 7, 634-639. [CrossRef]

16. Gao, M.; Huang, H.; Liu, Z.; Li, X.; Sutherland, J. Design and Optimization of the Slide Guide System of Hydraulic Press Based on Energy Loss Analysis. Energies 2016, 9, 434. [CrossRef]

17. Wang, Q.; Liu, F.; Li, C. An integrated method for assessing the energy efficiency of machiningworkshop. J. Clean. Prod. 2013, 52, 122-133. [CrossRef]

18. Vijayaraghavan, A.; Dornfeld, D. Automated energy monitoring of machine tools. CIRP Ann.-Manuf. Technol. 2010, 59, 21-24. [CrossRef]

19. Duflou, J.R.; Sutherland, J.W.; Dornfeld, D.; Herrmann, C.; Jeswiet, J.; Kara, S.; Hauschild, M.; Kellens, K. Towards energy and resource efficient manufacturing: A processes and systems approach. CIRP Ann.-Manuf. Technol. 2012, 61, 587-609. [CrossRef]

20. Zein, A.; Li, W.; Herrmann, C.; Kara, S. Energy Efficiency Measures for the Design and Operation of Machine Tools: An Axiomatic Approach. In Glocalized Solutions for Sustainability in Manufacturing; Hesselbach, J., Herrmann, C., Eds.; Springer: Berlin/Heidelberg, Germany, 2011.

21. Dornfeld, D.A. Moving towards green and sustainable manufacturing. Int. J. Precis. Eng. Manuf.-Green Technol. 2014, 1, 63-66. [CrossRef]

22. Lu, S.M. A review of high-efficiency motors: Specification, policy, and technology. Renew. Sustain. Energy Rev. 2016, 59, 1-12. [CrossRef]

23. O'Driscoll, E.; O'Donnell, G.E. Industrial power and energy metering-a state-of-the-art review. J. Clean. Prod. 2013, 41, 53-64. [CrossRef]

24. Gao, M.; Huang, H.; Li, X.; Liu, Z. A Novel Method to Quickly Acquire the Energy Efficiency for Piston Pumps. J. Dyn. Syst. Meas. Control-Trans. ASME 2016, 138, 101004-101012. [CrossRef]

25. Gao, M.; Liu, Z.; Wang, Y. A novel method to quick acquire efficiency characteristics for three phase induction motor. China Mech. Eng. 2016, 27, 1755-1759.

26. Gao, M.; Li, X.; Huang, H.; Liu, Z.; Li, L.; Zhou, D. Energy-saving Methods for Hydraulic Presses Based on Energy Dissipation Analysis. Procedia CIRP 2016, 48, 331-335. [CrossRef]

27. Gao, M.; Huang, H.; Li, X.; Liu, Z. Carbon emission analysis and reduction for stamping process chain. Int. J. Adv. Manuf. Technol. 2017, 91, 667-678. [CrossRef]

28. Tao, J.; Li, L.; Yu, S.; Peng, Q. In Modular Modeling Method for Energy Analysis of the Mechanical Servo Press. In Proceedings of the ASME 2015 International Design Engineering Technical Conferences and Computers and Information in Engineering Conference, Boston, MA, USA, 2-5 August 2015; p. V004T05A025.

29. Li, L.; Yu, S.; Peng, Q. In Energy Modeling Method Based on FBS Framework for Energy Efficiency Analysis. In Proceedings of the ASME 2016 International Design Engineering Technical Conferences and Computers and Information in Engineering Conference, Charlotte, NC, USA, 21-24 August 2016; p. V004T05A050.

30. Li, W. Efficiency of Manufacturing Processes; Springer: Berlin, Germany, 2015.

31. Fereshteh-Saniee, F.; Montazeran, M. A comparative estimation of the forming load in the deep drawing process. J. Mater. Process. Technol. 2003, 140, 555-561. [CrossRef]

32. Thiruvarudchelvan, S.; Lewis, W. Deep drawing with blank holder force approximately proportional to the punch force. J. Eng. Ind. 1990, 112, 278-285. [CrossRef]

33. Cooper, D.R.; Rossie, K.E.; Gutowski, T.G. The energy requirements and environmental impacts of sheet metal forming: An analysis of five forming processes. J. Mater. Process. Technol. 2017, 244, 116-135. [CrossRef]

34. Gao, M.; Huang, H.; Wang, Q.; Liu, Z.; Li, X. Energy consumption analysis on sheet metal forming: Focusing on the deep drawing processes. Int. J. Adv. Manuf. Technol. 2018, 96, 3893-3907. [CrossRef]

35. Li, L.; Huang, H.; Zhao, F.; Zou, X.; Mendis, G.; Luan, X.; Liu, Z.; Sutherland, J. Modeling and Analysis of the Process Energy for Cylindrical Drawing. J. Manuf. Sci. Eng.-Trans. ASME 2018, 141, 021001. [CrossRef]

36. Ingarao, G.; Lorenzo, R.D.; Micari, F. Sustainability issues in sheet metal forming processes: An overview. J. Clean. Prod. 2011, 19, 337-347. [CrossRef]

37. Rahimifard, S.; Seow, Y.; Childs, T. Minimising Embodied Product Energy to support energy efficient manufacturing. CIRP Ann.-Manuf. Technol. 2010, 59, 25-28. [CrossRef]

38. Liu, C.; Cai, W.; Jia, S.; Zhang, M.; Guo, H.; Hu, L.; Jiang, Z. Emergy-based evaluation and improvement for sustainable manufacturing systems considering resource efficiency and environment performance. Energy Convers. Manag. 2018, 177, 176-189. [CrossRef] 
39. Liu, C.; Wei, C.; Zhang, C.; Ma, M.; Rao, W.; Li, W.; Kang, H.; Gao, M. Developing the ecological compensation criterion of industrial solid waste based on emergy for sustainable development. Energy 2018, 157, 940-948.

40. Göschel, A.; Sterzing, A.; Schönherr, J. Balancing procedure for energy and material flows in sheet metal forming. CIRP J. Manuf. Sci. Technol. 2011, 4, 170-179. [CrossRef]

41. Åkerström, P. Modelling and Simulation of Hot Stamping. Ph.D. Thesis, Luleå University of Technology, Luleå, Sweden, 2006.

42. Karbasian, H.; Tekkaya, A.E. A review on hot stamping. J. Mater. Process. Technol. 2010, 210, $2103-2118$. [CrossRef]

43. Göschel, A.; Schieck, F.; Schönherr, J. Method for energy and resource balancing demonstrated as an example of the hot sheet metal production process. CIRP Ann.-Manuf. Technol. 2012, 61, 399-402. [CrossRef]

44. Shi, C.W.P.; Rugrungruang, F.; Yeo, Z.; Gwee, K.H.K.; Ng, R.; Song, B. Identifying carbon footprint reduction opportunities through energy measurements in sheet metal part manufacturing. In Glocalized Solutions for Sustainability in Manufacturing; Springer: Berlin/Heidelberg, Germany, 2011; pp. 389-394.

45. Camoirano, R.; Dellepiane, G. Variable frequency drives for MSF desalination plant and associated pumping stations. Desalination 2005, 182, 53-65. [CrossRef]

46. Su, C.L.; Chung, W.L.; Yu, K.T. An Energy-Savings Evaluation Method for Variable-Frequency-Drive Applications on Ship Central Cooling Systems. IEEE Trans. Ind. Appl. 2014, 50, 1286-1294.

47. Zheng, J.M.; Zhao, S.D.; Wei, S.G. Application of self-tuning fuzzy PID controller for a SRM direct drive volume control hydraulic press. Control Eng. Pract. 2009, 17, 1398-1404. [CrossRef]

48. Pugi, L.; Pagliai, M.; Nocentini, A.; Lutzemberger, G.; Pretto, A. Design of a hydraulic servo-actuation fed by a regenerative braking system. Appl. Energy 2017, 187, 96-115. [CrossRef]

49. Zheng, J.M.; Zhao, S.d.; Wei, S.G. Fuzzy iterative learning control of electrohydraulic servo system for SRM direct-drive volume control hydraulic press. J. Cent. South Univ. (Engl. Ed.) 2010, 17, 316-322. [CrossRef]

50. Lovrec, D.; Kastrevc, M.; Ulaga, S. Electro-hydraulic load sensing with a speed-controlled hydraulic supply system on forming-machines. Int. J. Adv. Manuf. Technol. 2009, 41, 1066-1075. [CrossRef]

51. Wang, L.; Book, W.J.; Huggins, J.D. Application of Singular Perturbation Theory to Hydraulic Pump Controlled Systems. IEEE/ASME Trans. Mechatron. 2012, 17, 251-259. [CrossRef]

52. Du, C.; Plummer, A.R.; Johnston, D.N. Performance analysis of an energy-efficient variable supply pressure electro-hydraulic motion control system. Control Eng. Pract. 2016, 48, 10-21. [CrossRef]

53. Lin, Y.; Shi, Y.; Burton, R. Modeling and Robust Discrete-Time Sliding-Mode Control Design for a Fluid Power Electrohydraulic Actuator (EHA) System. IEEE/ASME Trans. Mechatron. 2013, 18, 1-10. [CrossRef]

54. Chen, C.Y.; Liu, L.Q.; Cheng, C.C.; Chiu, T.C. Fuzzy controller design for synchronous motion in a dual-cylinder electro-hydraulic system. Control Eng. Pract. 2008, 16, 658-673. [CrossRef]

55. Locateli, C.C.; Teixeira, P.L.; Pieri, E.R.D.; Krus, P.; Negri, V.J.D. Digital hydraulic system using pumps and on/off valves controlling the actuator. In Proceedings of the 8th FPNI Ph.D. Symposium on Fluid Power, Lappeenranta, Finland, 11-13 June 2014; p. V001T01A009.

56. Scheidl, R.; Linjama, M.; Schmidt, S. Is the future of fluid power digital? Proc. Inst. Mech. Eng. Part I J. Syst. Control Eng. 2012, 226, 721-723. [CrossRef]

57. Huova, M.; Laamanen, A. Control of three-chamber cylinder with digital valve system. In Proceedings of the Second Workshop on Digital Fluid Power, Linz, Austria, 12-13 November 2009.

58. Heybroek, K.; Sahlman, M. A hydraulic hybrid excavator based on multi-chamber cylinders and secondary control-Design and experimental validation. Int. J. Fluid Power 2018, 19, 91-105. [CrossRef]

59. Heitzig, S.; Sgro, S.; Theissen, H. Energy Efficiency of Hydraulic Systems with Shared Digital Pumps. Int. J. Fluid Power 2012, 13, 49-57. [CrossRef]

60. Axin, M.; Eriksson, B.; Krus, P. Flow versus pressure control of pumps in mobile hydraulic systems. Proc. Inst. Mech. Eng. Part I J. Syst. Control Eng. 2014, 228, 245-256. [CrossRef]

61. Xu, B.; Cheng, M.; Yang, H.; Zhang, J.; Sun, C. A Hybrid Displacement/Pressure Control Scheme for an Electrohydraulic Flow Matching System. IEEE/ASME Trans. Mechatron. 2015, 20, 2771-2782. [CrossRef]

62. Li, L.; Huang, H.H.; Zhao, F.; Liu, Z.F. A coordinate method applied to partitioned energy-saving control for grouped hydraulic presses. J. Manuf. Syst. 2016, 41, 102-110. [CrossRef]

63. Li, L.; Huang, H.; Zhao, F.; Sutherland, J.W.; Liu, Z. An Energy-Saving Method by Balancing the Load of Operations for Hydraulic Press. IEEE/ASME Trans. Mechatron. 2017, 22, 2673-2683. [CrossRef] 
64. Triet, H.H.; Ahn, K.K. Comparison and assessment of a hydraulic energy-saving system for hydrostatic drives. Proc. Inst. Mech. Eng. Part I J. Syst. Control Eng. 2011, 225, 21-34. [CrossRef]

65. Ho, T.H.; Ahn, K.K. Modeling and simulation of hydrostatic transmission system with energy regeneration using hydraulic accumulator. J. Mech. Sci. Technol. 2010, 24, 1163-1175. [CrossRef]

66. Abdel-Baqi, O.; Nasiri, A.; Miller, P. Dynamic Performance Improvement and Peak Power Limiting Using Ultracapacitor Storage System for Hydraulic Mining Shovels. IEEE Trans. Ind. Electron. 2015, 62, 3173-3181. [CrossRef]

67. Abdel-Baqi, O.J.; Nasiri, A.; Miller, P.J. Energy Management for an 8000 hp Hybrid Hydraulic Mining Shovel. IEEE Trans. Ind. Appl. 2016, 52, 5041-5050. [CrossRef]

68. Minav, T.; Immonen, P.; Laurila, L.; Vtorov, V. Electric energy recovery system for a hydraulic forklift-theoretical and experimental evaluation. IET Electr. Power Appl. 2011, 5, 377-385. [CrossRef]

69. Lin, T.; Wang, Q.; Hu, B.; Gong, W. Research on the energy regeneration systems for hybrid hydraulic excavators. Autom. Constr. 2010, 19, 1016-1026. [CrossRef]

70. Wang, T.; Wang, Q.; Lin, T. Improvement of boom control performance for hybrid hydraulic excavator with potential energy recovery. Autom. Constr. 2013, 30, 161-169. [CrossRef]

71. Wang, T.; Wang, Q. An Energy-Saving Pressure-Compensated Hydraulic System with Electrical Approach. IEEE/ASME Trans. Mechatron. 2014, 19, 570-578. [CrossRef]

72. Li, L.; Huang, H.; Li, X.; Liu, Z. An Improved Energy Matching Method to Utilize the Potential Energy of Large-sized Hydraulic Press at Multi-system Level. Procedia CIRP 2017, 61, 547-552. [CrossRef]

73. Li, L.; Huang, H.; Zhao, F.; Triebe, M.J.; Liu, Z. Analysis of a novel energy-efficient system with double-actuator for hydraulic press. Mechatronics 2017, 47, 77-87. [CrossRef]

74. Wei, W. Structural Optimization for Upper Beam of Isothermal Hydraulic Press. Appl. Mech. Mater. 2013, 423, 1936-1939. [CrossRef]

75. Wei, W. Lightweight Design for Lower Beam of NC Isothermal Hydraulic Press. Appl. Mech. Mater. 2013, 470, 463-466. [CrossRef]

76. Li, B.; Hong, J.; Wang, Z.; Liu, Z. An Innovative Layout Design Methodology for Stiffened Plate/Shell Structures by Material Increasing Criterion. J. Eng. Mater. Technol. 2013, 135, 203-214. [CrossRef]

77. Li, B.; Hong, J.; Liu, Z. Stiffness design of machine tool structures by a biologically inspired topology optimization method. Int. J. Mach. Tools Manuf. 2014, 84, 33-44. [CrossRef]

78. Zhang, W.; Lu, B.C.; Fan, G.; Chong, M. Lightweight Design Optimization of Large-Tonnage Hydraulic Press Body Structure. Adv. Mater. Res. 2013, 748, 406-410. [CrossRef]

79. Hou, B.; Wang, W.; Li, S.; Lin, Z.; Xia, Z.C. Stochastic analysis and robust optimization for a deck lid inner panel stamping. Mater. Des. 2010, 31, 1191-1199. [CrossRef]

80. Gantar, G.; Kuzman, K. Optimization of stamping processes aiming at maximal process stability. J. Mater. Process. Technol. 1999, 167, 237-243. [CrossRef]

81. Sun, G.; Li, G.; Gong, Z.; Cui, X.; Yang, X.; Li, Q. Multiobjective robust optimization method for drawbead design in sheet metal forming. Mater. Des. 2010, 31, 1917-1929. [CrossRef]

82. Gantar, G.; Pepelnjak, T.; Kuzman, K. Optimization of sheet metal forming processes by the use of numerical simulations. J. Mater. Process. Technol. 2002, 130, 54-59. [CrossRef]

83. Zhang, K.; Yong-Chao, X.U.; Zhang, S.H.; Wang, Z.T. Deep-drawing of Magnesium Alloy Sheets at Warm Temperatures. J. Mater. Process. Technol. 2004, 185, 147-151. [CrossRef]

84. Marumo, Y.; Saiki, H.; Ruan, L. Effect of sheet thickness on deep drawing of metal foils. J. Achiev. Mater. Manuf. Eng. 2007, 20, 479-482.

85. Agrawal, A.; Reddy, N.V.; Dixit, P.M. Determination of optimum process parameters for wrinkle free products in deep drawing process. J. Mater. Process. Technol. 2007, 191, 51-54. [CrossRef]

86. Zein, H.; Sherbiny, M.E.; Abd-Rabou, M.; Shazly, M.E. Thinning and spring back prediction of sheet metal in the deep drawing process. Mater. Des. 2014, 53, 797-808. [CrossRef]

87. Liu, P.; Ku, T.; Kim, J.; Kang, B.; Liu, P. AIP Conference Proceedings [AIP NUMISHEET 2014: The 9th International Conference and Workshop on Numerical Simulation of 3D Sheet Metal Forming Processes: Part A Benchmark Problems and Results and Part B General Papers-Melbourne, Australia, 6-10 January 2014)],-Investigation on process parameters of flexible stretch forming process using orthogonal experiment design. AIP Conf. Proc. 2013, 1567, 1093-1097. 
88. Padmanabhan, R.; Oliveira, M.C.; Alves, J.L.; Menezes, L.F. Influence of process parameters on the deep drawing of stainless steel. Finite Elem. Anal. Des. 2007, 43, 1062-1067. [CrossRef]

89. Chen, X.; Dongwon, J.; Youngki, S. Evaluation Influence of Process Parameters on Wheel Disk Forming Process Using Orthogonal Design Method. Adv. Technol. Plast. 2008, 9, 398.

90. Hu, W.; Yao, L.G.; Hua, Z.Z. Optimization of sheet metal forming processes by adaptive response surface based on intelligent sampling method. J. Mater. Process. Technol. 2008, 197, 77-88. [CrossRef]

91. Zhang, W.; Wang, D. Optimization of Sheet Metal Forming Process Parameters by Artificial Neural Network and Orthogonal Test Method. In International Conference on Electrical, Mechanical and Industrial Engineering; Atlantis Press: Paris, France, 2016.

92. Kitayama, S.; Huang, S.; Yamazaki, K. Optimization of variable blank holder force trajectory for springback reduction via sequential approximate optimization with radial basis function network. Struct. Multidiscip. Optim. 2013, 47, 289-300. [CrossRef]

93. Costa, N.R.; Pereira, Z.L. Multiple response optimization: A global criterion-based method. J. Chemom. 2010, 24, 333-342. [CrossRef]

94. Marler, R.T.; Arora, J.S. The weighted sum method for multi-objective optimization: New insights. Multidiscip. Optim. 2010, 41, 853-862. [CrossRef]

95. Liu, W.; Yang, Y. Multi-objective optimization of sheet metal forming process using Pareto-based genetic algorithm. J. Mater. Process. Technol. 2008, 208, 499-506.

96. Zhou, J.; Wang, B.; Lin, J.; Fu, L. Optimization of an aluminum alloy anti-collision side beam hot stamping process using a multi-objective genetic algorithm. Arch. Civ. Mech. Eng. 2013, 13, 401-411. [CrossRef]

97. Zhou, J. A Method to Optimize Aluminum Alloy Door Impact Beam Stamping Process Using NSGA-II. Mater. Sci. Forum 2013, 773-774, 89-94. [CrossRef]

98. Ingarao, G.; Lorenzo, R.D.; Micari, F. Analysis of stamping performances of dual phase steels: A multi-objective approach to reduce springback and thinning failure. Mater. Des. 2009, 30, 4421-4433. [CrossRef]

99. Xiao, W.; Wang, B.; Zhou, J.; Ma, W.; Yang, L. Optimization of aluminium sheet hot stamping process using a multi-objective stochastic approach. Eng. Optim. 2016, 48, 2173-2189. [CrossRef]

100. Marretta, L.; Ingarao, G.; Lorenzo, R.D. Design of sheet stamping operations to control springback and thinning: A multi-objective stochastic optimization approach. Int. J. Mech. Sci. 2010, 52, 914-927. [CrossRef]

101. Maravelias, C.T. General framework and modeling approach classification for chemical production scheduling. Aiche J. 2012, 58, 1812-1828. [CrossRef]

102. Tian, G.; Zhou, M.C.; Li, P.; Tian, G.; Zhou, M.C.; Li, P.; Tian, G.; Zhou, M.C.; Li, P.; Tian, G. Disassembly Sequence Planning Considering Fuzzy Component Quality and Varying Operational Cost. IEEE Trans. Autom. Sci. Eng. 2017, 15, 748-760. [CrossRef]

103. Gahm, C.; Denz, F.; Dirr, M.; Tuma, A. Energy-efficient scheduling in manufacturing companies: A review and research framework. Eur. J. Oper. Res. 2015, 248, 744-757. [CrossRef]

104. Garetti, M.; Taisch, M. Sustainable manufacturing: Trends and research challenges. Prod. Plan. Control 2012, 23, 83-104. [CrossRef]

105. Merkert, L.; Harjunkoski, I.; Isaksson, A.; Säynevirta, S.; Saarela, A.; Sand, G. Scheduling and energy-Industrial challenges and opportunities. Comput. Chem. Eng. 2015, 72, 183-198. [CrossRef]

106. Castro, P.M.; Grossmann, I.E.; Zhang, Q. Expanding Scope and Computational Challenges in Process Scheduling. Comput. Chem. Eng. 2018, 114, 14-42. [CrossRef]

107. Harjunkoski, I.; Maravelias, C.T.; Castro, P.M.; Engell, S.; Grossmann, I.E.; Hooker, J.; Méndez, C.; Sand, G.; Wassick, J.; Bongers, P. Scope for industrial applications of production scheduling models and solution methods. Comput. Chem. Eng. 2014, 62, 161-193. [CrossRef]

108. Duflou, J. ICT and Energy Efficiency the Case for Manufacturing; European Communities: Luxembourg, 2009.

109. Mouzon, G.; Yildirim, M.B.; Twomey, J. Operational methods for minimization of energy consumption of manufacturing equipment. Int. J. Prod. Res. 2007, 45, 4247-4271. [CrossRef]

110. Mashaei, M.; Lennartson, B. Energy Reduction in a Pallet-Constrained Flow Shop through On-Off Control of Idle Machines. IEEE Trans. Autom. Sci. Eng. 2013, 10, 45-56. [CrossRef]

111. Luo, H.; Du, B.; Huang, G.Q.; Chen, H.; Li, X. Hybrid flow shop scheduling considering machine electricity consumption cost. Int. J. Prod. Econ. 2013, 146, 423-439. [CrossRef]

112. Lu, C.; Gao, L.; Li, X.; Pan, Q.; Wang, Q. Energy-efficient permutation flow shop scheduling problem using a hybrid multi-objective backtracking search algorithm. J. Clean. Prod. 2017, 144, 228-238. [CrossRef] 
113. May, G.K.; Stahl, B.; Taisch, M.; Prabhu, V. Multi-objective genetic algorithm for energy-efficient job shop scheduling. Int. J. Prod. Res. 2015, 53, 7071-7089. [CrossRef]

114. Shrouf, F.; Ordieres-Meré, J.; García-Sánchez, A.; Ortega-Mier, M. Optimizing the production scheduling of a single machine to minimize total energy consumption costs. J. Clean. Prod. 2014, 67, 197-207. [CrossRef]

115. B€ahre, D.; Swat, M.; Steuer, P.; Trapp, K. Energy consumption: One criterion for the sustainable design of process chains. In Sustainable Manufacturing; Springer: Berlin/Heidelberg, Germany, 2012; pp. 163-168.

116. Tian, G.; Ren, Y.; Feng, Y.; Zhou, M.; Zhang, H.; Tan, J. Modeling and Planning for Dual-objective Selective Disassembly Using AND/OR Graph and Discrete Artificial Bee Colony. IEEE Trans. Ind. Inform. 2019, 15, 2456-2468. [CrossRef]

117. Bruzzone, A.A.G.; Anghinolfi, D.; Paolucci, M.; Tonelli, F. Energy-aware scheduling for improving manufacturing process sustainability: A mathematical model for flexible flow shops. CIRP Ann.-Manuf. Technol. 2012, 61, 459-462. [CrossRef]

118. Zhang, H.; Zhao, F.; Fang, K.; Sutherland, J.W. Energy-conscious flow shop scheduling under time-of-use electricity tariffs. CIRP Ann.-Manuf. Technol. 2014, 63, 37-40. [CrossRef]

119. Yildirim, M.B.; Mouzon, G. Single-Machine Sustainable Production Planning to Minimize Total Energy Consumption and Total Completion Time Using a Multiple Objective Genetic Algorithm. IEEE Trans. Eng. Manag. 2012, 59, 585-597. [CrossRef]

120. Zhang, L.; Li, X.; Gao, L.; Zhang, G. Dynamic rescheduling in FMS that is simultaneously considering energy consumption and schedule efficiency. Int. J. Adv. Manuf. Technol. 2016, 87, 1387-1399. [CrossRef]

121. Tang, D.; Dai, M.; Salido, M.A.; Giret, A. Energy-efficient dynamic scheduling for a flexible flow shop using an improved particle swarm optimization. Comput. Ind. 2015, 30, 223-232. [CrossRef]

122. Wang, H.; Jiang, Z.; Wang, Y.; Zhang, H.; Wang, Y. A two-stage optimization method for energy-saving flexible job-shop scheduling based on energy dynamic characterization. J. Clean. Prod. 2018, 188, 575-588. [CrossRef]

123. Zhang, Y.; Wang, J.; Liu, Y. Game theory based real-time multi-objective flexible job shop scheduling considering environmental impact. J. Clean. Prod. 2017, 167, 665-679. [CrossRef]

124. Mokhtari, H.; Hasani, A. An Energy-Efficient Multi-Objective Optimization for Flexible Job-Shop Scheduling Problem. Comput. Chem. Eng. 2017, 104, 339-352. [CrossRef]

125. Gutowski, T.; Dahmus, J.; Thiriez, A. Electrical energy requirements for manufacturing processes. In 13th CIRP International Conference on Life Cycle Engineering; CIRP International Leuven: Leuven, Belgium, 2006.

126. Ding, J.Y.; Song, S.; Wu, C. Carbon-efficient scheduling of flow shops by multi-objective optimization. Eur. J. Oper. Res. 2015, 248, 758-771. [CrossRef]

127. Zhang, H.; Zhao, F.; Sutherland, J.W. Scheduling of a Single Flow Shop for Minimal Energy Cost under Real-time Electricity Pricing. J. Manuf. Sci. Eng. 2017, 139, 014502. [CrossRef]

128. Paolucci, M.; Anghinolfi, D.; Tonelli, F. Facing energy-aware scheduling: A multi-objective extension of a scheduling support system for improving energy efficiency in a moulding industry. Soft Comput. 2017, 21, 3687-3698. [CrossRef]

129. Liu, Y.; Dong, H.; Lohse, N.; Petrovic, S.; Gindy, N. An Investigation into Minimising Total Energy Consumption and Total Weighted Tardiness in Job Shops. J. Clean. Prod. 2013, 65, 87-96. [CrossRef]

130. Nonaka, Y.; Erdős, G.; Kis, T.; Nakano, T.; Váncza, J. Scheduling with alternative routings in CNC workshops. CIRP Ann.-Manuf. Technol. 2012, 61, 449-454. [CrossRef]

131. Ji, M.; Wang, J.Y.; Lee, W.C. Minimizing resource consumption on uniform parallel machines with a bound on makespan. Comput. Oper. Res. 2013, 40, 2970-2974. [CrossRef]

132. Fang, K.; Uhan, N.; Zhao, F.; Sutherland, J.W. A new approach to scheduling in manufacturing for power consumption and carbon footprint reduction. J. Manuf. Syst. 2011, 30, 234-240. [CrossRef]

133. Yin, L.; Li, X.; Gao, L.; Lu, C.; Zhang, Z. A novel mathematical model and multi-objective method for the low-carbon flexible job shop scheduling problem, considering productivity, energy efficiency and noise reduction. Sustain. Comput. Inform. Syst. 2017, 13, 15-30.

134. Fox, K.; Im, S.; Moseley, B. Energy efficient scheduling of parallelizable jobs. Theor. Comput. Sci. 2018, 726, 30-40. [CrossRef]

135. Wang, S.; Lu, X.; Li, X.X.; Li, W.D. A systematic approach of process planning and scheduling optimization for sustainable machining. J. Clean. Prod. 2015, 87, 914-929. [CrossRef] 
136. Liu, Q.; Zhang, Y.; Zhou, Y. Integrated optimization of cutting parameters and scheduling for reducing carbon emissions. J. Mech. Eng. 2017, 53, 24. [CrossRef]

137. Zeng, Z.; Hong, M.; Li, J.; Man, Y.; Liu, H.; Li, Z.; Zhang, H. Integrating process optimization with energy-efficiency scheduling to save energy for paper mills. Appl. Energy 2018, 225, 542-558. [CrossRef]

138. Koltsaklis, N.E.; Giannakakis, M.; Georgiadis, M.C. Optimal Energy Planning and Scheduling of Microgrids. Chem. Eng. Res. Des. 2018, 131, 318-323. [CrossRef]

139. Li, L.; Huang, H.; Zhao, F.; Liu, Z. Operation scheduling of multi-hydraulic press system for energy consumption reduction. J. Clean. Prod. 2017, 165, 1407-1419. [CrossRef]

(C) 2019 by the authors. Licensee MDPI, Basel, Switzerland. This article is an open access article distributed under the terms and conditions of the Creative Commons Attribution (CC BY) license (http://creativecommons.org/licenses/by/4.0/). 